\title{
Application Of A Method Of 1-D Equivalent Wall To Multidimensional Geometries: Impact On Building Energy Performance
}

\author{
Julien Quinten ${ }^{1}$, Véronique Feldheim ${ }^{1}$ \\ ${ }^{1}$ UMONS - Faculty of Engineering, Mons, Belgium
}

\begin{abstract}
Some building energy software consider heat flux as being 1-D and are not able to consider the dynamic thermal effects of multidimensional details. We have proposed a new equivalent wall method: multidimensional geometries are replaced by 1-D threelayer walls. Equivalent walls of six thermal bridges of a building are validated for realistic boundary conditions (average error on heat flux $<0.5 \mathrm{~W} / \mathrm{m}$, error on energy transferred $<0.5 \%$ ). By using those equivalent walls in energy simulation of the studied building, impact of thermal bridges on cooling needs is multiplied by three and heating/cooling power can be quite different $(15 / 22 \%$ of the maximal value), compared to a classic evaluation.
\end{abstract}

\section{Introduction}

In the light of the urgency of reducing the use of fossil fuels and the greenhouse gas emissions, a strong focus is given to the building energy performance due to the significant contribution of the building sector in the energy consumption of the European Union (40\% of the primary energy). Energy simulation tools are needed to evaluate, predict and optimise building energy needs via numerical simulations. Those tools must be improved as some hypotheses have been made to ease and accelerate the computing process but lead to some inaccuracies.

Our work focuses on thermal bridges, multidimensional details of the building envelope and responsible for $4 \%$ up to $39 \%$ of the heat losses of a building (Martin et. al, 2012). In most of building energy software, heat flux is considering as being 1-D and a 1-D time series model is commonly used to solve the heat conduction problem (Karambakkam et al., 2005). The steady-state additional heat flux through a multidimensional detail is easily taken into account in this kind of software whereas the real dynamic effects are not considered. That can lead to inaccurate results, mainly if the inertia of the thermal bridge is different from that of the clear wall (Kosny and Kossecka, 2002), and they can cause a wrong sizing of heating and cooling systems.

According to some studies (Kosny and Kossecka, 2002; Martin et al., 2011; Viot et al., 2015; Baba and Ge, 2016), there is no simplified or approximated method correctly evaluating the heat flux through any multidimensional geometry in dynamic conditions. In order to avoid a multidimensional modelling integrated to the building simulation over one year, their proposition is to use a reduced model. Moreover, this model must be simple to integrate into any building energy simulation software and require as low computational resources as possible.

Keeping these objectives in mind, we have developed a mixed equivalent wall method. In this paper, this method is presented and applied to six thermal bridges of a lowenergy building. Accuracy of their equivalent walls is studied in realistic boundary conditions and the impact of the thermal bridges modelling on the numerical evaluation of building energy needs is analysed.

Some studies (Ge and Baba, 2015 and 2017) have been already performed on heavy structured buildings, as the most critical case is high levels of insulation and thermal mass with high disparity in thermal properties at the junctions. In their studies, the equivalent wall method has better results than a classic method (using the linear thermal transmittance $\Psi$ of the thermal bridge), however the difference with the yearly heating and cooling loads of their 3-D modelling is quite significant. Another type of building, a light structure, is studied in this paper.

\section{Method}

\section{Mixed equivalent wall method}

Principle of the equivalent wall method is to replace the multidimensional detail by a 1-D multilayer equivalent wall (Figure 1): they must have the same thermal behaviour (Martin et al., 2012). To define the equivalent wall, which is a continuous model, the thermal resistance and the heat capacity of each layer must be determined, and then the physical properties $(\mathrm{k}, \rho, \mathrm{c})$ are deduced to be introduced in the building energy software. According to the literature (Martin et al., 2012; Kosny and Kossecka, 2002) and our own experience (Quinten, 2018), the optimum between accuracy and calculation time is a three-layer equivalent wall.
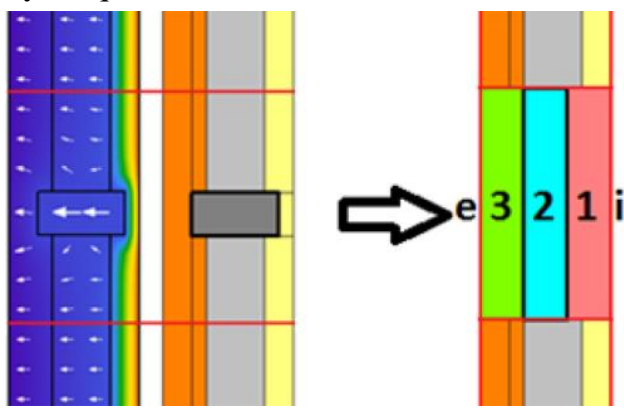

Figure 1: 2-D detail is replaced by a 1-D equivalent wall. 
In our method, two notions are mixed: the structure factors' theory (Kossecka and Kosny, 1997) and the wall response in the frequency domain. All equations, details and references about the theory can be found in a previous paper (Quinten and Feldheim, 2019).

According to Kossecka and Kosny, two structures with the same values of thermal resistance $R$, heat capacity $C$ and structure factors $\left(\phi_{\mathrm{ii}}, \phi_{\mathrm{ie}}, \phi_{\mathrm{ee}}\right)$ have similar thermal characteristics, even if they can be different in details. These five numbers must be identical for the multidimensional detail and its equivalent wall. The structure factors impose conditions on the values of response factors of the 1-D equivalent wall and are linked to the values of $R_{j}$ and $C_{j}(j=1,2,3$ in this case).

Values of $R_{1}, R_{2}, R_{3}, C_{1}, C_{2}$ and $C_{3}$ are to be determined and there are four equations (respect of the values of $\mathrm{R}$, of $\mathrm{C}$ and of two structure factors, the third one being linked to the other two structure factors): two parameters are free and an infinity of 1-D wall respects these equations. The selected equivalent wall is the one, among this infinity, minimising an objective function $\mathrm{F}$, which compares its thermal response to that of the initial geometry in harmonic conditions. Those harmonic conditions are a sinus indoor temperature (unit amplitude, 24h-period) and a sum of nine harmonics of different periods and amplitudes, representative of the climate of Brussels (Belgium), for outdoor temperature (Quinten and Feldheim, 2018). Only the heat flux through the inside surface is studied, as it is the one used in the energy balance of the building, and the objective function $F$ compares this flux over time for the real geometry $\left(\mathrm{q}_{\mathrm{i}}\right)$ and for the equivalent wall ( $\left.\mathrm{q}_{\mathrm{i}}{ }^{\prime}\right)$ via Eq. (1) $(\mathrm{t}=0 \mathrm{~h}$ corresponds to $1^{\text {st }}$ January 00:00, the results are analysed from $t=400 \mathrm{~h}$ to avoid influence of initial conditions).

$$
F=\sqrt{\sum_{t=400 h}^{t=200 h}\left(q_{i}(t)^{2}-q_{i}{ }^{\prime}(t)^{2}\right)}
$$

Our mixed method can be summarised in four steps:

1) Calculation of the thermal resistance, heat capacity and structure factors of the 2-D/3-D detail by performing a steady-state simulation thanks to a simulation software.

2) Calculation of the response $q_{i}(t)$ to harmonic boundary conditions for the 2-D/3-D detail by performing a dynamic simulation thanks to a simulation software.

3) Determination of the equivalent wall thanks to a homemade MATLAB script: a high number of combinations of $\mathrm{R}_{2}-\mathrm{R}_{3}$ values are tested and, for each combination, the values of $\mathrm{R}_{1}, \mathrm{C}_{1}, \mathrm{C}_{2}$ and $\mathrm{C}_{3}$ are deduced to respect the values of $\mathrm{R}, \mathrm{C}$ and structure factors. The response $\mathrm{q}_{\mathrm{i}}{ }^{\prime}(\mathrm{t})$ to harmonic boundary conditions is then calculated (thanks to the transfer functions in the frequency domain, deduced from those in the Laplace domain (Pipes, 1957)) and the objective function $F$ is determined. The equivalent wall minimising the F-value is selected.

4) Determination of physical properties (k, c) of each layer of the equivalent wall, from the values of their thermal resistance and heat capacity and by fixing the value of their thickness and their density $(\rho)$.

\section{Presentation of the building and the thermal bridges}

The studied building is a fictitious one. It is a two-storey detached house (simple rectangular shape) and each storey is divided in four equal parts by internal walls. Its characteristics are those of a passive house (good thermal insulation and air-tightness) and they are listed in Table 1. Heat flux is really $1-\mathrm{D}$ on $43 \%$ of the outside envelope surface area.

Table 1: Geometrical and thermal characteristics of the studied fictitious building.

\begin{tabular}{|c|c|c|c|c|}
\hline $\mathbf{V}$ & $\mathbf{A}_{\text {floors }}$ & $\mathbf{A}_{\text {loss }}$ & $\mathbf{A}_{\text {windows }}$ & $\mathbf{n}_{50}$ \\
\hline $\mathbf{m}^{\mathbf{3}}$ & $\mathbf{m}^{\mathbf{2}}$ & $\mathbf{m}^{\mathbf{2}}$ & $\mathbf{m}^{\mathbf{2}}$ & $\mathbf{h}^{\mathbf{1}}$ \\
\hline 558 & $2 \times 87$ & 414 & 27.2 & 0.6 \\
\hline $\mathbf{U}_{\text {wall }}$ & $\mathbf{U}_{\text {roof }}$ & $\mathbf{U}_{\text {floor slab }}$ & $\mathbf{U}_{\text {window }}$ & $\mathbf{g}_{\text {glazing }}$ \\
\hline $\mathbf{W} / \mathbf{m}^{\mathbf{2}} \mathbf{K}$ & $\mathbf{W} / \mathbf{m}^{\mathbf{2}} \mathbf{K}$ & $\mathbf{W} / \mathbf{m}^{\mathbf{2}} \mathbf{K}$ & $\mathbf{W} / \mathbf{m}^{\mathbf{2}} \mathbf{K}$ & - \\
\hline 0.175 & 0.121 & 0.126 & 0.57 & 0.585 \\
\hline
\end{tabular}

The following hypotheses are made for the building modelling:

- A one-zone model is used (single indoor air temperature);

- Ground temperature is $10^{\circ} \mathrm{C}$, whatever the depth;

- Door, chimney, gutter, cables, slight slope of the roof, etc. are not considered;

- Bricks are perfectly joined;

- Air- and water-tightness membranes are not modelled (no thermal influence);

- Solar protections are used in summer;

- No superposition of thermal bridges is assumed;

- Outside the thermal bridges' areas, the layer made-up of insulation and wood studs can be replaced by an equivalent layer (thermal properties are deduced by an area weighting of those of both materials). This procedure has been validated by Karambakkam (2005) and the good accuracy of this simplification has been verified.

Six thermal bridges are selected and analysed: roof external wall junction (TB1, Figure 2), intermediate floor - external wall junction (TB2, Figure 3), floor slab external wall junction (TB3, Figure 4), window frame external wall junction (TB4, Figure 5), internal wall external wall junction (TB5, Figure 6) and corner (TB6, Figure 7). They are 2-D thermal bridges, but for some ones a slice of the detail $(\mathrm{L}=0.2 \mathrm{~m})$ is studied. Materials are listed in Table 2 .

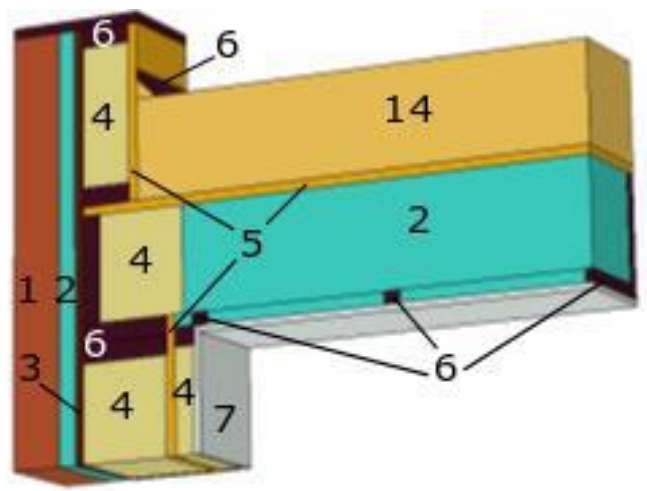

Figure 2: TB1: Roof-external wall junction. 
The floor slab - external wall junction (TB3) is a particular case with three zones of temperature: it is in contact with outdoor temperature, indoor temperature and ground temperature. The thermal bridge is divided into two parts by using a methodology proposed by Aguilar et al. (2014). An equivalent wall is determined for each part (upper part and lower part, Figure 4), the corresponding boundary conditions are applied, and the contribution of each part is summed.

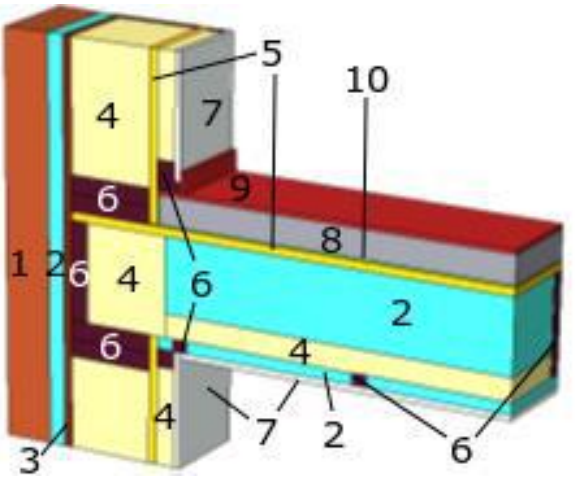

Figure 3: TB2: Intermediate floor-external wall junction.

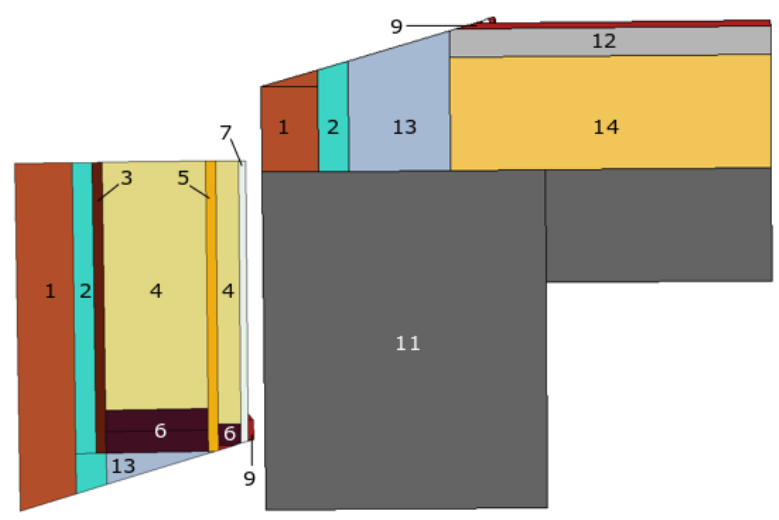

Figure 4: TB3: Separation of the floor slab-external wall junction (upper part-lower part).

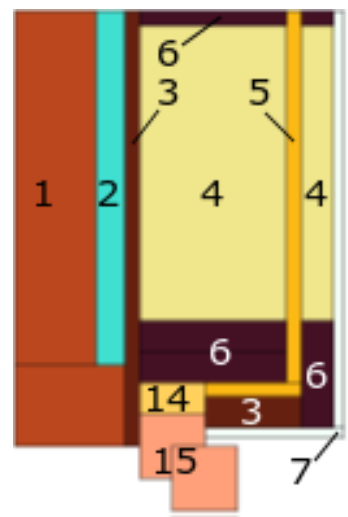

Figure 5: TB4: Window frame - external wall junction.

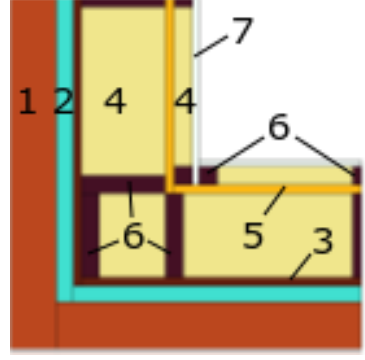

Figure 6: TB5: Corner.

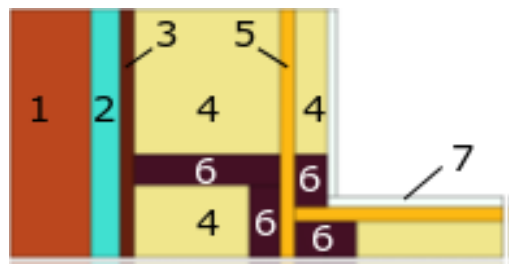

Figure 7: TB6: Internal wall-external wall junction (symmetry is considered).

Table 2: Materials of the studied building.

\begin{tabular}{|c|c|}
\hline Number & Material \\
\hline 1 & Brick \\
\hline 2 & Air \\
\hline 3 & Fibreboard of wood \\
\hline 4 & Rockwool \\
\hline 5 & OSB panel \\
\hline 6 & Wood \\
\hline 7 & Plaster \\
\hline 8 & Tiling \\
\hline 9 & Polyolefin foam \\
\hline 10 & Reinforced concrete \\
\hline 11 & Cement-based screed \\
\hline 12 & Aerated concrete \\
\hline 13 & Polyurethane \\
\hline 14 & Frame (wood) \\
\hline 15 & \\
\hline
\end{tabular}

Properties of the six thermal bridges are listed in Table 3.

Table 3: Properties of the thermal bridges.

\begin{tabular}{|c|c|c|c|c|}
\hline & $\Psi$ & $\mathbf{L}$ & $\mathbf{R}$ & C \\
\hline & W/m.K & $\mathbf{m}$ & $\mathrm{m}^{2} . \mathrm{K} / \mathrm{W}$ & $\mathrm{kJ} / \mathrm{m}^{2} . \mathrm{K}$ \\
\hline TB1 & -0.039 & 37.4 & 8.30 & 156 \\
\hline TB2 & 0.044 & 37.4 & 4.42 & 458 \\
\hline TB3 up. & \multirow{2}{*}{0.021} & \multirow{2}{*}{37.4} & 5.39 & 258 \\
\hline TB3 low. & & & 6.49 & 1139 \\
\hline TB4 & 0.048 & 68 & 3.05 & 267 \\
\hline TB5 & -0.107 & 16.9 & 9.66 & 217 \\
\hline \multirow[t]{3}{*}{ TB6 } & 0.005 & $2 \times 16.9$ & 5.24 & 300 \\
\hline & $\mathbf{S}_{1-D}$ & $\phi_{\mathrm{ii}}$ & $\phi_{\mathrm{ie}}$ & $\phi_{\text {ee }}$ \\
\hline & $\mathbf{m}^{2} / \mathbf{m}$ & - & - & - \\
\hline TB1 & 1.90 & 0.214 & 0.059 & 0.668 \\
\hline TB2 & 0.86 & 0.448 & 0.053 & 0.446 \\
\hline TB3 up. & 0.61 & 0.118 & 0.063 & 0.756 \\
\hline TB3 low. & 0.90 & 0.056 & 0.010 & 0.924 \\
\hline TB4 & 0.62 & 0.183 & 0.065 & 0.687 \\
\hline TB5 & 1.50 & 0.074 & 0.039 & 0.848 \\
\hline TB6 & 0.31 & 0.244 & 0.057 & 0.641 \\
\hline
\end{tabular}




\section{Validation of equivalent walls}

In order to check if the thermal bridges and their equivalent walls have the same thermal behaviour, evolutions over time of heat fluxes through the inside surface are analysed in the same conditions (from $\mathrm{t}=0 \mathrm{~h}$ to $t=2000 h$ ). Hourly meteorological data of Brussels (Belgium) are used for the outdoor temperature $\mathrm{T}_{\mathrm{e}}$ and the solar heat flux (south orientation, a solar absorption factor of 0.75 is used). A realistic variable indoor temperature $T_{i}$ is used (Figure 8). Standard values of surface heat transfer coefficients are fixed $\left(\mathrm{U}_{\mathrm{i}}=8 \mathrm{~W} / \mathrm{m}^{2} \mathrm{~K}, \mathrm{U}_{\mathrm{e}}=23 \mathrm{~W} / \mathrm{m}^{2} \mathrm{~K}\right)$. These boundary conditions are different from those used to define the equivalent wall. Time step is $1 \mathrm{~h}$.

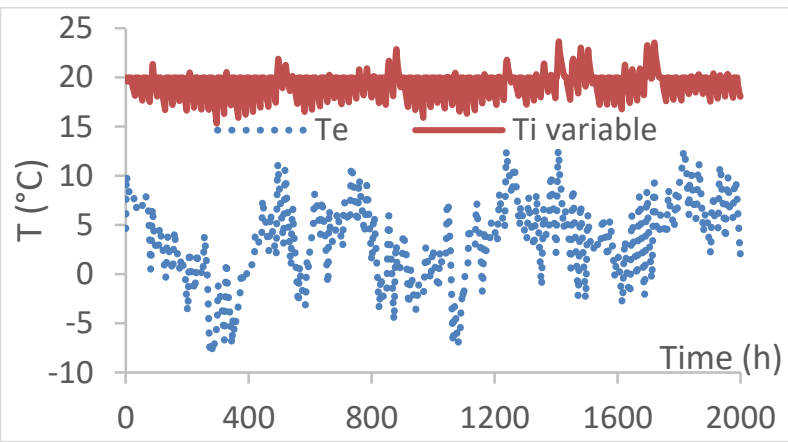

Figure 8: Environment temperatures over time.

Numerical simulations of heat conduction problems are performed with the COMSOL Multiphysics software (2015). For dynamic simulations, meshing consists of triangular elements and quadratic shape functions are used: the number of degrees of freedom is between 5000 and 150000 for the 2-D and 3-D studied geometries. The initial condition is $20^{\circ} \mathrm{C}$ in the entire domain.

The following error indicators are used to quantify the accuracy of the model over the 2000h-period (the results for the initial 2-D/3-D geometry are the reference):

- $\quad \varepsilon_{\mathrm{av}}$ : average error on heat flux over the studied period $[\mathrm{W} / \mathrm{m}]$;

- $\varepsilon_{\max }$ : maximal error on heat flux over the studied period $[\mathrm{W} / \mathrm{m}]$;

- E: relative error on the temporal integral value of heat flux over the studied period (rectangle rule) [\%].

Moreover, the results of a classic 1-D evaluation of the heat flux through the thermal bridge are also compared: a dynamic evaluation is performed for the 1-D clear wall (without thermal bridge) and the linear transmittance $\Psi$ (static contribution) of the 2-D thermal bridge of length $\mathrm{L}$ is added via Eq. (2).

$$
q_{i, \text { classic }}(t)=q_{i, 1 D}(t)+\Psi \times L \times\left(T_{e}(t)-T_{i}(t)\right)(2)
$$

\section{Building energy simulation}

Three thermal bridge models are used to evaluate the building energy performance:

- No consideration of thermal bridges effects;

- Static modelling of thermal bridges, via their $\Psi$ value (the total contribution of the thermal bridges is $2.615 \mathrm{~W} / \mathrm{K}$ );
- Dynamic modelling of thermal bridges, by replacing the thermal bridges by their equivalent walls.

Building energy simulations are performed with the TRNSYS17 software (2012) and the time step is $1 \mathrm{~h}$. Considering a time step of ten minutes, there is a difference on yearly energy needs of some tenths of a percent but the relative differences between results of the three models are similar.

Hourly meteorological data of Brussels (Belgium) are used. Heating set point is $20^{\circ} \mathrm{C}$ from 6:00 to 9:00 and from $16: 00$ to $22: 00$ during the week and from $8: 00$ to $22: 00$ during the weekend, and it is $16^{\circ} \mathrm{C}$ the rest of the time. Cooling set point is always $25^{\circ} \mathrm{C}$. Heating power is limited to $4 \mathrm{~kW}$ and cooling power to $2 \mathrm{~kW}$. Heating system is switched off from $1^{\text {st }}$ May to $30^{\text {th }}$ September.

Daily average value of internal gains is around $600 \mathrm{~W}$ (variation according to occupancy), mechanical ventilation rate is $0.35 \mathrm{~h}^{-1}$ and the air leakage rate is $0.024 \mathrm{~h}^{-1}$ in real conditions (corresponds to the result of a blower-door test respecting the passive label). For the ventilation system, there is a heat recovery device (effectiveness $=85 \%$ ) without any by-pass.

For each thermal bridges modelling, heating and cooling energy needs, overheating, energy power and evolution of indoor temperature are analysed in three cases: without any system, with heating and cooling systems and with a heating system only. "Without any system" means that only solar heat flux, outdoor temperature and air infiltration are taken into account as solicitations (no air ventilation, internal gains and heating/cooling systems). The reference case is the one without thermal bridges effects.

\section{Results}

\section{Validation of the equivalent walls}

Evolutions over time of heat fluxes through inside surface of real detail and of its equivalent wall are compared to the classic evaluation $(1 \mathrm{D}+\Psi)$, for each thermal bridge of the building, on Figures 9-14. Results are zoomed on the $1200 \mathrm{~h}-1368 \mathrm{~h}$ period (20 ${ }^{\text {th }}$ February to $26^{\text {th }}$ February).

Curves of the equivalent walls are almost superimposed to that of the multidimensional details. There is a slight gap in two cases, the window frame - external wall junction (Figure 12) and the internal wall - external wall junction (Figure 14), without significant time lag.

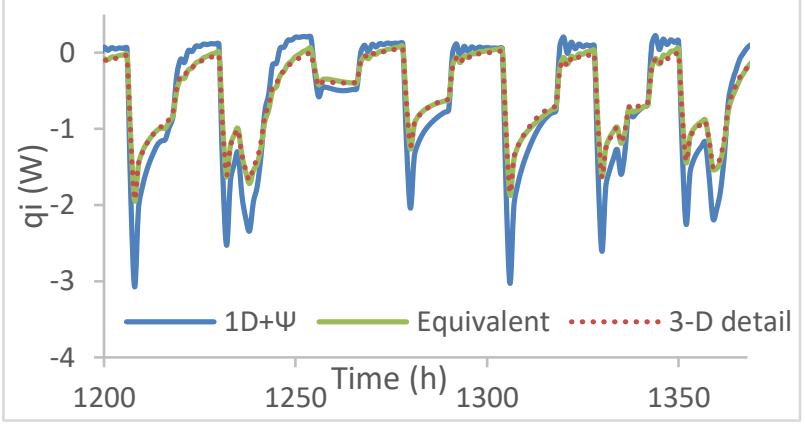

Figure 9: Inner heat flux over time, models of roofexternal wall junction (TB1). 


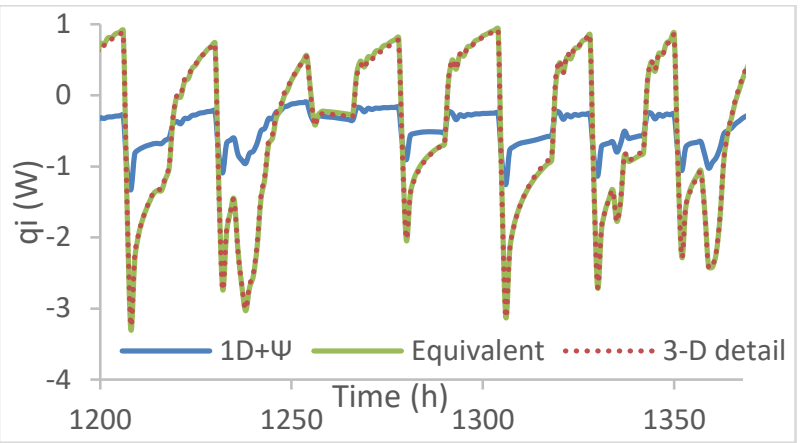

Figure 10: Inner heat flux over time, models of intermediate floor - external wall junction (TB2).

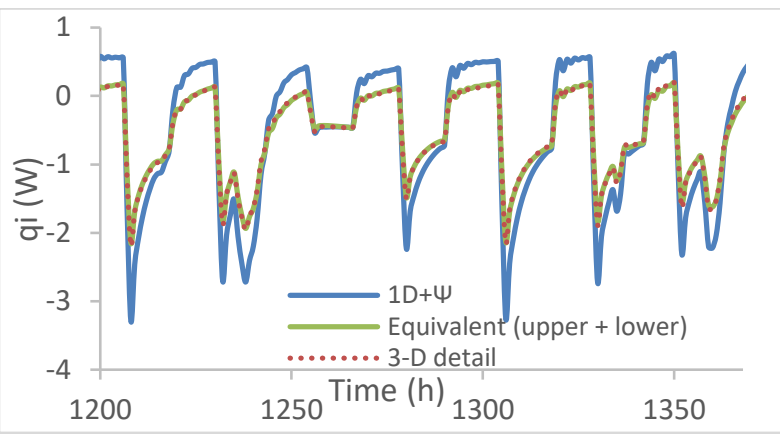

Figure 11: Inner heat flux over time, models of floor slab - external wall junction (TB3).

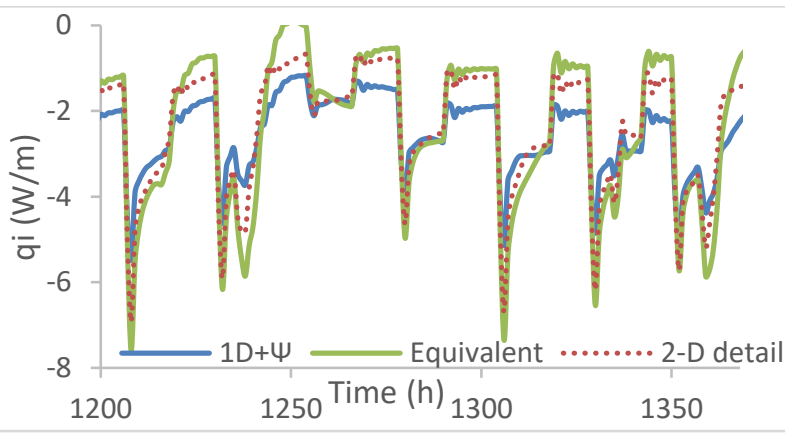

Figure 12: Inner heat flux over time, models of window frame-external wall junction (TB4).

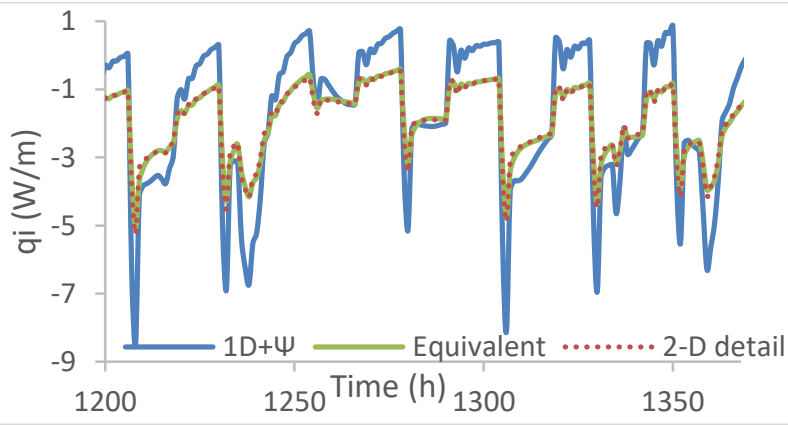

Figure 13: Inner heat flux over time, models of corner (TB5).

Results are less accurate for the classic evaluation: amplitude of variations of heat fluxes is higher for some cases and is lower for the other ones.

Error indicators for equivalent walls and classic evaluations $(1 \mathrm{D}+\Psi)$ are listed in Table 4.

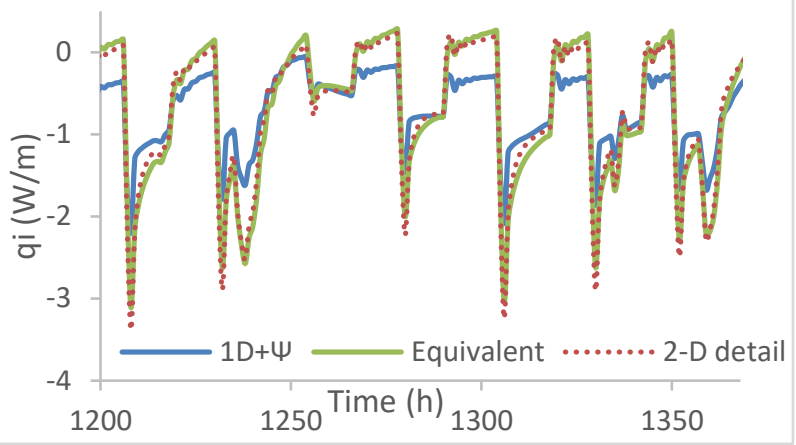

Figure 14: Inner heat flux over time, models of internal wall - external wall junction (TB6).

Less accurate results are obtained for the window frame external wall junction (TB4), but they remain satisfactory: a fraction of the heat flux is quickly transmitted through the frame part and the other fraction of heat flux is transmitted through the wall with a higher time constant. When there exist thermal phenomena with very different time constants, one 1-D equivalent wall could be insufficient to correctly model the reality. An average error of $0.4 \mathrm{~W} / \mathrm{m}$ is obtained for the equivalent wall and of $0.6 \mathrm{~W} / \mathrm{m}$ for the classic evaluation. Value of heat flux integral is largely better for the equivalent wall: an error of $0.05 \%$ against an error of $9 \%$ for the classic way.

Table 4: Accuracy of thermal bridge models: error indicators.

\begin{tabular}{|c|c|c|c|c|}
\hline & Model & $\mathbf{E a v}$ & $\mathbf{E m a x}$ & $\mathbf{E}$ \\
\cline { 2 - 5 } & - & $\mathbf{W} / \mathbf{m}$ & $\mathbf{W} / \mathbf{m}$ & $\mathbf{\%}$ \\
\hline \multirow{2}{*}{ TB1 } & Equiv & 0.15 & 0.69 & 0.01 \\
\cline { 2 - 5 } & 1D $+\Psi$ & 1.48 & 10.4 & 17 \\
\hline \multirow{2}{*}{ TB2 } & Equiv & 0.13 & 1.03 & 0.09 \\
\cline { 2 - 5 } & 1D $+\Psi$ & 4.29 & 16.2 & 5.4 \\
\hline \multirow{2}{*}{ TB3 } & Equiv & 0.10 & 0.86 & 0.51 \\
\cline { 2 - 5 } & 1D $+\Psi$ & 1.95 & 9.50 & 0.47 \\
\hline \multirow{2}{*}{ TB4 } & Equiv & 0.42 & 2.01 & 0.05 \\
\cline { 2 - 5 } & 1D $+\Psi$ & 0.62 & 2.93 & 8.9 \\
\hline \multirow{2}{*}{ TB5 } & Equiv & 0.09 & 0.77 & 0.04 \\
\cline { 2 - 5 } & 1D $+\Psi$ & 1.05 & 6.08 & 8.4 \\
\hline \multirow{2}{*}{ TB6 } & Equiv & 0.11 & 0.51 & 0.28 \\
\cline { 2 - 5 } & $1 \mathrm{D}+\Psi$ & 0.37 & 2.09 & 2.2 \\
\hline
\end{tabular}

For the equivalent walls of other thermal bridges, average and maximal errors are lower than $0.15 \mathrm{~W} / \mathrm{m}$ and $1 \mathrm{~W} / \mathrm{m}$ respectively. The maximal error on value of heat flux integral is $0.5 \%$. Average error on inner heat flux is 3 to 35 times higher for a classic evaluation and error on integral value can reach some percent $(17 \%$ in the worst case).

Average errors can be multiplied by the length of each thermal bridge and the total error of each method is estimated by summing the contribution of each thermal bridge. Total average error is $51 \mathrm{~W}$ for the equivalent wall method and $361 \mathrm{~W}$ for the classic method (multiplying factor of 7 and difference of about $300 \mathrm{~W}$ ).

These results validate our equivalent wall method in conditions different from the training data and confirm a more accurate evaluation of the thermal bridges effects than with a classic consideration. 


\section{Impact of the thermal bridges modelling on building thermal behaviour}

A first analysis is performed for a simulation without any system to evaluate the natural reaction of the building to external variations of solar heat flux and air temperature. That can highlight the differences of building behaviour induced by the three thermal bridge models. Evolutions of indoor temperature for each model and of outdoor temperature are shown on Figure 15 (zoomed view on the beginning of the year).

On Figure 15, variations of outdoor temperature are largely higher than those of indoor temperatures. High level of walls insulation, inertia of some concrete layers and the contact with the ground at constant temperature participate to smooth indoor temperature.

Indoor temperature without considering the thermal bridges is almost always higher than that with static thermal bridge model (maximal difference of $0.2^{\circ} \mathrm{C}$ ) and their dynamic seems similar.

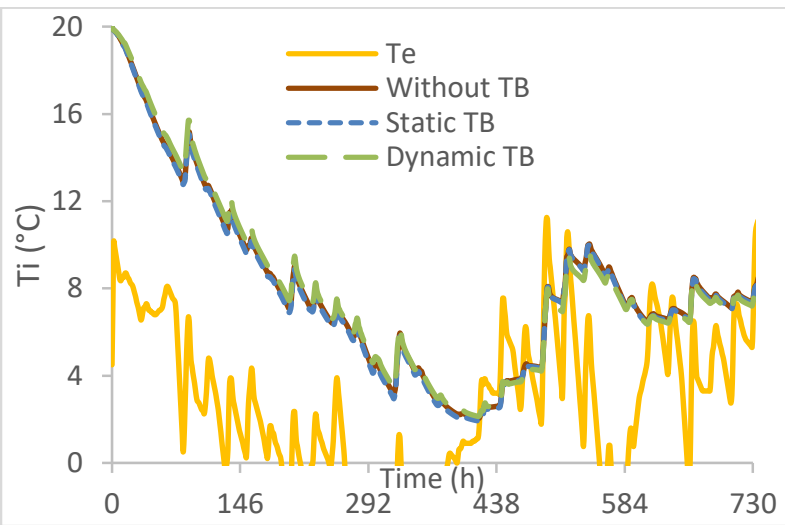

Figure 15: Outdoor and indoor temperatures over timeno system.

By comparing the results between the cases with static thermal bridges and dynamic thermal bridges, yearly average indoor temperatures are close $\left(16.2\right.$ and $\left.16.1^{\circ} \mathrm{C}\right)$ but variations of indoor temperature seem slightly lower and slower by using the dynamic model (for example, the average slope is $-0.08^{\circ} \mathrm{C} / \mathrm{h}$ over the first 80 hours and the temperature is between 2.1 and $28.8^{\circ} \mathrm{C}$ over the year while these values are $-0.09^{\circ} \mathrm{C} / \mathrm{h}$ and between 1.9 and $29.2^{\circ} \mathrm{C}$ for the static model).

These observations tend to conclude that the global inertia of the building is slightly higher, in this case, if the dynamic behaviour of thermal bridges is considered.

A simulation with air infiltration, ventilation, internal gains and heating and cooling systems is performed to evaluate the difference in energy needs of the building for the three studied models. Yearly heating and cooling energy needs are listed in Table 5. Energy needs are divided by floor area $\left(2 \times 87.22 \mathrm{~m}^{2}\right)$. Given the results of the previous section, the real dynamic effects of thermal bridges are well considered with our equivalent wall method: using this method improves evaluation of the impact of thermal bridges on the building energy behaviour and it might reasonably be assumed that the results are then more accurate, compared to using a static consideration or no consideration of thermal bridges.

Table 5: Yearly heating and cooling needs according to TB model.

\begin{tabular}{|c|c|c|c|}
\hline & \multicolumn{3}{|c|}{ Heating energy needs } \\
\hline & $\begin{array}{c}\text { Without } \\
\text { TB }\end{array}$ & $\begin{array}{c}\text { Static } \\
\text { TB }\end{array}$ & $\begin{array}{c}\text { Dynamic } \\
\text { TB }\end{array}$ \\
\hline & $\mathbf{k W h} / \mathbf{m}^{2}$ & $\mathrm{kWh} / \mathbf{m}^{2}$ & $\mathbf{k W h} / \mathbf{m}^{2}$ \\
\hline \multirow[t]{4}{*}{ Yearly } & 8.66 & $\begin{array}{c}9.15 \\
+5.7 \% \\
\end{array}$ & $\begin{array}{c}9.04 \\
+4.4 \% \\
\end{array}$ \\
\hline & \multicolumn{3}{|c|}{ Cooling energy needs } \\
\hline & $\begin{array}{c}\text { Without } \\
\text { TB } \\
\end{array}$ & $\begin{array}{c}\text { Static } \\
\text { TB }\end{array}$ & $\begin{array}{c}\text { Dynamic } \\
\text { TB }\end{array}$ \\
\hline & $\mathbf{k W h} / \mathrm{m}^{2}$ & $\mathrm{kWh} / \mathrm{m}^{2}$ & $\mathrm{kWh} / \mathrm{m}^{2}$ \\
\hline Yearly & 7.75 & $\begin{array}{c}7.53 \\
-2.8 \% \\
\end{array}$ & $\begin{array}{c}7.07 \\
-8.8 \% \\
\end{array}$ \\
\hline
\end{tabular}

In Table 5, energy needs are very low (considering that the passive label requires yearly heating energy needs lower than $15 \mathrm{kWh} / \mathrm{m}^{2}$ ): $8.7 \mathrm{kWh} / \mathrm{m}^{2}$ for heating and 7.8 $\mathrm{kWh} / \mathrm{m}^{2}$ for cooling, without considering the thermal bridges effects.

About $90 \%$ of the heat losses of the building are heat losses through walls or windows and the thermal bridges increase by about $5 \%$ the heating energy needs: static and dynamic models lead to a similar result. Dynamic model of thermal bridges leads to slightly lower heating energy needs, due to a low increase of global inertia of the building in this case.

At the opposite, the thermal bridges decrease the cooling energy needs: that seems logic as heat losses are increased and thus the risk to overtake $25^{\circ} \mathrm{C}$ is reduced (only when outdoor temperature is higher than indoor temperature, the thermal bridges can increase overheating, but it is quite unusual). Their impact is multiplied by 3 if their dynamic effects are considered (-9\%), compared to the case where the static effects are considered (-3\%). Dynamic model of thermal bridges leads to lower cooling energy needs, also due to a slight increase of global inertia of the building.

On Figure 16 and 17, evolutions of heating and cooling powers over a week are shown for the simulations with static and dynamic models of thermal bridges (the red curve is the difference between the values of both cases).

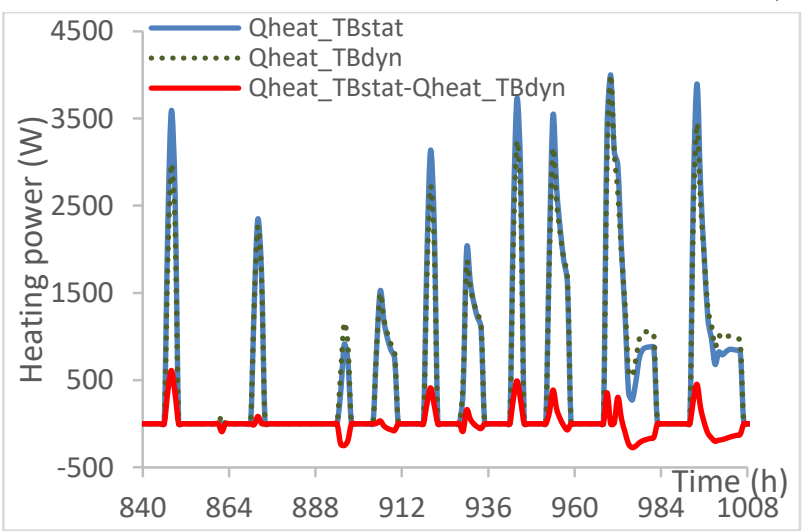

Figure 16: Heating energy power over a week: comparison of TB models. 


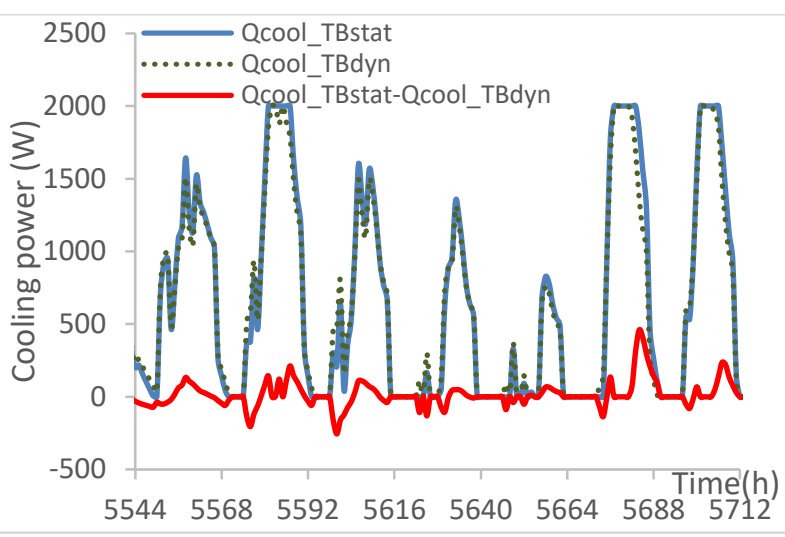

Figure 17: Cooling energy power over a week: comparison of TB models.

On Figure 16, difference of heating power between both curves is quite balanced and the positive and negative differences are compensated over the year. It is observed that this difference reaches up to $600 \mathrm{~W}(15 \%$ of the maximal heating power) and average difference is around $150 \mathrm{~W}$ (considering only the hours during which a heating power is needed over the year).

On Figure 17, it is observed that difference of cooling power reaches up to $450 \mathrm{~W}(22.5 \%$ of the maximal cooling power) and average difference is around $80 \mathrm{~W}$ (considering only the hours during which a cooling power is needed over the year).

A last analysis is performed by cancelling the cooling system to study the problems of overheating. Degree hours of overheating are listed in Table 6, for different threshold temperatures.

Table 6: Degree hours of overheating of the building for some threshold temperatures, according to TB model.

\begin{tabular}{|c|c|c|c|}
\hline Threshold & $\begin{array}{c}\text { Without } \\
\text { TB }\end{array}$ & $\begin{array}{c}\text { Static } \\
\text { TB }\end{array}$ & $\begin{array}{c}\text { Dynamic } \\
\text { TB }\end{array}$ \\
\hline${ }^{\circ} \mathbf{C}$ & ${ }^{\circ}$ C.h & ${ }^{\circ}$ C.h & ${ }^{\circ}$ C.h \\
\hline $\mathbf{2 3}$ & 20421 & 19601 & 18647 \\
& & $-4.0 \%$ & $-8.7 \%$ \\
\hline $\mathbf{2 5}$ & 12974 & 12325 & 11542 \\
& & $-5.0 \%$ & $-11.2 \%$ \\
\hline $\mathbf{2 6}$ & \multirow{2}{*}{9822} & 9255 & 8522 \\
& & $-5.8 \%$ & $-13.2 \%$ \\
\hline $\mathbf{2 8}$ & 4681 & 4306 & 3787 \\
& & $-8.0 \%$ & $-19.1 \%$ \\
\hline
\end{tabular}

In Table 6, it is observed that taking into account the thermal bridges decreases overheating. It is the same justification as for the decrease of cooling needs (both are linked).

By using a temperature threshold of $23-28^{\circ} \mathrm{C}$, the number of degree hours of overheating decreases by about $4-8 \%$ if a static model of thermal bridges is used and by around 9-19\% if a dynamic model of thermal bridges is used, compared to the case without thermal bridge. Higher is the temperature threshold, higher is the impact of the model of thermal bridges.

The impact of thermal bridges on degree hours of overheating is multiplied by 2 to 2.5 if the dynamic model is used instead of the static model. Dynamic model of thermal bridges leads to a lower value of degree hours of overheating, again due to a slight increase of the global inertia of the building.

\section{Conclusion}

Aim of this paper was to evaluate the impact of using the equivalent wall method, for thermal bridges modelling, on energy needs of a particular building, with high levels of thermal insulation and air-tightness.

Principles of our equivalent wall method are linked to the structure factors and to the heat fluxes in the frequency domain. This method allows to consider the dynamic thermal effects of multidimensional geometries in any building energy software considering the heat flux as being 1-D: evaluation of energy needs of a building is then more precise and the sizing of energy systems is more reliable. Moreover the thermo-physical properties of each layer of equivalent walls are easy to introduce into those software, and they are valid for any boundary condition or time step.

Six thermal bridges of a fictitious wooden-structure house are studied: heat flux is 1-D on only $43 \%$ of the external surface area. In dynamic and realistic boundary conditions, equivalent walls have a thermal behaviour very close to that of the real details and are validated with boundary conditions (hourly weather data, with solar heat flux) different from those (harmonic signals, without solar heat flux) used to define the equivalent wall. They are more accurate than the classic 1-D evaluation, as the total average error on heat flux through the thermal bridges is seven times lower.

This building has very low yearly heating and cooling energy needs $\left(<10 \mathrm{kWh} / \mathrm{m}^{2}\right)$. Using a static or dynamic modelling of thermal bridges in energy simulation of this building is compared. The dynamic model of thermal bridges leads to a lower value of degree hours of overheating and lower heating/cooling energy needs: this is due to a higher global inertia of the building (light structure), in this case, by considering the dynamic effects of the thermal bridges.

Between both cases, there is no significant difference in heating needs. The impact of thermal bridges on yearly cooling needs is multiplied by three by using the dynamic model, even if the absolute difference remains quite low (80 kWh). Nevertheless, a quite significant difference can exist for the required power by the systems at a particular moment: this difference reaches up to $15 \%$ of the maximal value for heating power and up to $22.5 \%$ for cooling power.

Of course, before generalising the conclusions, impact of thermal bridges modelling must be studied on other types of building (depending on thermal insulation level, renovated or new building, heavy or light structure, etc.). Ideally, those results should be compared to those of a 3D dynamic modelling.

To improve the results when phenomena with very different time constants occur in real geometry, two 1-D equivalent walls in parallel could be used. 
Moreover, an adaptation is needed to use our equivalent wall method for a multizone model of the building as the heat flux transferred through the thermal bridge to the whole building can be correctly calculated but not the repartition of the flux to each impacted room. Some developments are under way and the first results are encouraging.

A last interesting improvement is to create an inventory or general rules to determine the equivalent walls of various configurations of 2-D/3-D details.

\section{Nomenclature}

$A$, surface area $\left[\mathrm{m}^{2}\right]$

$c$, specific heat $[\mathrm{J} / \mathrm{kg} . \mathrm{K}]$

$C$, heat capacity $\left[\mathrm{J} / \mathrm{m}^{2} . \mathrm{K}\right]$

$e$, outdoor/exterior (subscript)

$E$, error on value of heat flux integral [\%]

$F$, error function $[\mathrm{W}]$ or $[\mathrm{W} / \mathrm{m}]$

$g$, solar factor [-]

$i$, indoor/interior (subscript)

$k$, heat conductivity $[\mathrm{W} / \mathrm{m} . \mathrm{K}]$

$L$, length [m]

$n_{50}$, air leakage rate $(\Delta \mathrm{p}=50 \mathrm{~Pa})\left[\mathrm{h}^{-1}\right]$

$q_{i}$, heat flux through inside surface $[\mathrm{W} / \mathrm{m}]$

$R$, thermal resistance $\left[\mathrm{m}^{2} . \mathrm{K} / \mathrm{W}\right]$

$t$, time $[\mathrm{h}]$ or $[\mathrm{s}]$

$T$, temperature $\left[{ }^{\circ} \mathrm{C}\right]$

$T B$, thermal bridge

$U$, heat transfer coefficient $\left[\mathrm{W} / \mathrm{m}^{2} . \mathrm{K}\right]$

$V$, volume $\left[\mathrm{m}^{3}\right]$

$\varepsilon$, error on heat flux value $[\mathrm{W} / \mathrm{m}]$

$\Psi$, linear thermal transmittance (thermal bridge) [W/m.K] $\rho$, density $\left[\mathrm{kg} / \mathrm{m}^{3}\right]$

$\phi_{i i}, \phi_{i e}, \phi_{e e}$, structure factors [-]

\section{References}

Aguilar, F., Solano, J.P., Vicente, P.G. (2014). Transient modeling of high-inertial thermal bridges in buildings using the equivalent wall method. Applied Thermal Engineering 67, 370-377.

Baba, F., Ge, H. (2016). Dynamic effect of balcony thermal bridges on the energy performance of a highrise residential building in Canada. Energy and Buildings 116, 78-88.

COMSOL Multiphysics 5.2 (2015). Reference Manual.

Ge, H., Baba, F. (2015). Dynamic effect of thermal bridges on the energy performance of a low-rise residential building. Energy and Buildings 105, 106118.
Ge, H., Baba, F. (2017). Effect of dynamic modeling of thermal bridges on the energy performance of residential buildings with high thermal mass for cold climates. Sustainable Cities and Society 34, 250-263.

Karambakkam, B.K., Nigusse, B., Spitler, J.D. (2005). A one-dimensional approximation for transient multidimensional conduction heat transfer in building envelopes. Proceedings from the $7^{\text {th }}$ Symposium on Building Physics in the Nordic Countries. Reykjavik (Iceland), 13-15 June 2005.

Kosny, J., Kossecka, E. (2002). Multidimensional heat transfer through complex building envelope assemblies in hourly energy simulation programs. Energy and Buildings 34, 445-454.

Kossecka, E., Kosny, J. (1997). Equivalent wall as a dynamic model of the complex thermal structure. Journal of Thermal Insulation and Building Envelopes 20, 249-268.

Martin, K., Erkoreka, A., Flores, I., Sala, J.M. (2011). Problems in the calculation of thermal bridges in dynamic conditions. Energy and Buildings 43, 529535.

Martin, K., Escudero, C., Erkoreka, A., Flores, I., Sala, J.M. (2012). Equivalent wall method for dynamic characterization of thermal bridges. Energy and Buildings 55, 704-714.

TRNSYS17 - Solar Energy Laboratory - University of Wisconsin-Madison (2012). TRNSYS 17: User manual.

Pipes, L. A. (1957). Matrix analysis of heat transfer problem. Journal of the Franklin Institute 263, no. 3, 195-205.

Quinten, J. (2018). Dynamic modelling of thermal bridge: Impact on the energy performance of low-energy buildings, University of Mons, $\mathrm{PhD}$ Thesis. Mons (Belgium).

Quinten, J., Feldheim, V. (2018). Equivalent wall method for dynamic modelling of thermal bridges in lowenergy building: application and parametric study. Proceedings from the $10^{\text {th }}$ International Conference on System Simulation in Buildings. Liège (Belgium), 10-12 December 2018.

Quinten, J., Feldheim, V. (2019). Mixed equivalent wall method for dynamic modelling of thermal bridges: Application to 2-D details of building envelope. Energy and Buildings 183, 697-712.

Viot, H., Sempey, A., Pauly, M., Mora, L. (2015). Comparison of different methods for calculating thermal bridges: Application to wood-frame buildings. Building and Environment 93, 339-348. 